\title{
Changing trends in intrauterine contraceptive device: from interval intrauterine contraceptive device to postpartum intrauterine contraceptive device: a prospective observational study in a tertiary care hospital in eastern Uttar Pradesh
}

\author{
Sneha Tyagi*, Vani Aditya, Reena Srivastava, Geeta Gupta
}

Department of Obstetrics, BRD Medical College, Gorakhpur, Uttar Pradesh, India

Received: 10 June 2016

Revised: 12 June 2016

Accepted: 16 June 2016

*Correspondence:

Dr. Sneha Tyagi,

E-mail: s.tyagi2711@gmail.com

Copyright: () the author(s), publisher and licensee Medip Academy. This is an open-access article distributed under the terms of the Creative Commons Attribution Non-Commercial License, which permits unrestricted non-commercial use, distribution, and reproduction in any medium, provided the original work is properly cited.

\section{ABSTRACT}

Background: The current outburst of Indian population (1.21 billion as per census 2011) is because of the lack of awareness and acceptance of contraception in the immediate postpartum period. Postpartum intrauterine contraceptive device (PPIUCD) insertion can do wonders and curb this unmet need of family planning if good counselling and proper insertion techniques are followed.

Methods: The present study was carried among 526 women in the department of obstetrics and gynaecology of Nehru Hospital in BRD medical college Gorakhpur, India. Intrauterine contraceptive device (IUCD) was inserted in 424 women in PPIUCD group and in 102 women in interval IUCD group after taking proper consent and following the WHO medical eligibility criteria for contraceptive use (MEC). Follow-up was done at 6 weeks and 6 months.

Results: The acceptance rate of PPIUCD was $30.34 \%$ as compared to $18 \%$ in interval IUCD group (p-value <0.05). The chief reason for declining the use of IUCD was fear of excessive pain and bleeding (26.3\%). Long term reversible method $(32 \%)$ was the main reason given for accepting IUCD. There was no perforation or any other major complication at the time of insertion in both the groups. Rate of expulsion was $5.7 \%$ in PPIUCD and $2.22 \%$ in interval IUCD group p-value (>0.05).

Conclusions: PPIUCD is a safe, effective, feasible and reversible method of contraception. It should be made a part of family health care programmes in India.

Keywords: PPIUCD interval IUCD acceptance expulsion

\section{INTRODUCTION}

The current outburst of Indian population (1.21 billion as per 2011 census) is because of the lack of awareness and acceptance of contraception in the post-partum period. Curbing this alarming rise in population is an area of immediate concern for the health policy makers. In India, around $65 \%$ of women in the first year postpartum have an unmet need for family planning. ${ }^{1}$ Postpartum family planning services are ideal way to reposit family planning back in India. PPIUCD is one of the most effective, long term and reversible family planning method. PPIUCD can reduce the number of unintended pregnancies and abortion related complications. The objective of the study was to know the acceptance rates of post-partum IUCD, to know the reasons for discontinuation of PPIUCD in follow up period, to study the side effects and complications of PPIUCD and to compare PPIUCD with interval IUCD with respect to above.

\section{METHODS}

The present study was carried among 526 women in obstetrics and gynaecology department of Nehru hospital 
of BRDMC Gorakhpur, India from $1^{\text {st }}$ June 2014 to $31^{\text {st }}$ May 2015. It was a prospective study done with the aim to assess the acceptance, safety, complications and rate of removal of PPIUCD in comparison to interval IUCD.

Data collection was done from $1^{\text {st }}$ August 2014 to $31^{\text {st }}$ March 2015 i.e. a period of 8 months. 424 women in PPIUCD group, 188 in vaginal delivery group and 158 in trans-caesarian delivery group. 102 women in interval IUCD group.

IUCD were inserted under full asepsis and with proper insertion techniques keeping in mind WHO MEC (medical eligibility criteria). ${ }^{12}$

At 6 week and 6 month follow up visits, history and clinical examination were repeated as per the predesigned proforma.

\section{RESULTS}

Total numbers of women, eligible for PPIUCD were 1398 after applying WHO MEC. Out of which 424 women accepted insertion of PPIUCD. Thus, the acceptance rate was $30.34 \%$. Total women eligible for interval IUCD were 562. IUCD was inserted in 102 women i.e. acceptance rate is $18 \%$. Overall, the acceptance rate of PPIUCD was significantly higher than interval IUCD ( $p$-value $<0.05)$.

Majority of the women who accepted PPIUCD belonged to the age group 26-30 years (44\%). In primiparous women, PPIUCD is a highly preferred method (45\%) over interval IUCD (20\%) which indicates its use as a method of spacing. Majority of women included in the study had a minimal primary education (42\% in PPIUCD and $48 \%$ in interval IUCD).

The chief reason for declining IUCD use was fear of excessive pain and bleeding $(26.3 \%)$ and refusal by partner or family $(18.9 \%)$. Long term reversible method (32\%) and high efficacy $(21 \%)$ were the main reasons given for accepting IUCD. There was no perforation or any other major complication at the time of insertion in both the groups. Majority of women in both the groups had easy insertion (97.17\% in PPIUCD and $82.3 \%$ in interval IUCD group). Only $2.8 \%$ women in PPIUCD group and $17.6 \%$ women in interval IUCD group had difficulty at the time of insertion which is statistically significant (p-value $<0.05$ ).

Expulsion rate of PPIUCD was $5.7 \%$ which is comparable to that of interval IUCD i.e. $2.22 \%$ (p-value $>0.05$ ) which signifies that with good insertion techniques and with trained insertors the expulsion rate of PPIUCD can be lowered. Spontaneous expulsion was seen in $16(8.5 \%)$ women in vaginal delivery group and 4 $(2.5 \%)$ women in transcaeserian group which is significant statistically (p-value <0.05). This lower expulsion rate after transcaesarean insertion as compared to vaginal insertion may be due to direct placement of IUCD at the fundus during caesarean section.

$17.9 \%(62 / 346)$ women in PPIUCD and $14.4 \%(13 / 90)$ women in interval group had some side effects. Excessive bleeding per vaginum (40.3\%) was the main side effect in PPIUCD group whereas it was present in $30.7 \%$ in interval IUCD group. On the other hand, excessive discharge per vaginum $(38.4 \%)$ was the chief complaint in interval IUCD group.

$38(10.9 \%)$ women got their IUCD removed in PPIUCD group in comparison to $15(16.6 \%)$ women in interval group (p-value $>0.05$ ). The demand for IUCD removal was mainly for the complaint of excessive discharge $\mathrm{p} / \mathrm{v}$ in interval IUCD (36\%) and excessive vaginal bleeding (35\%) in PPIUCD group. Continuation rates over a follow up period of 6 months were $83.2 \%$ in PPIUCD group and $81.1 \%$ in interval IUCD group (p-value $>0.05$ ). The continuation rates in transcaeserian group were statistically significant than vaginal group (p-value <0.05)

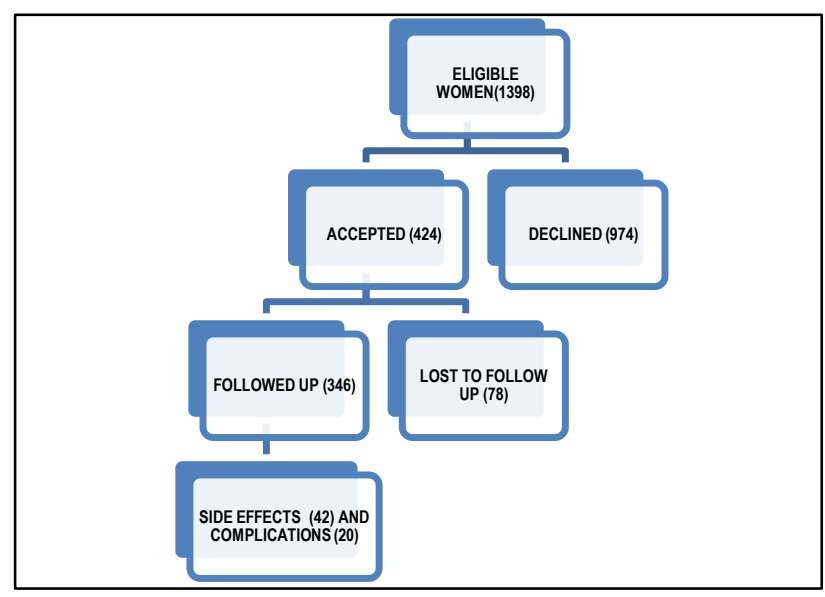

Figure 1: Flow chart showing recruitment of women and follow up of PPIUCD group.

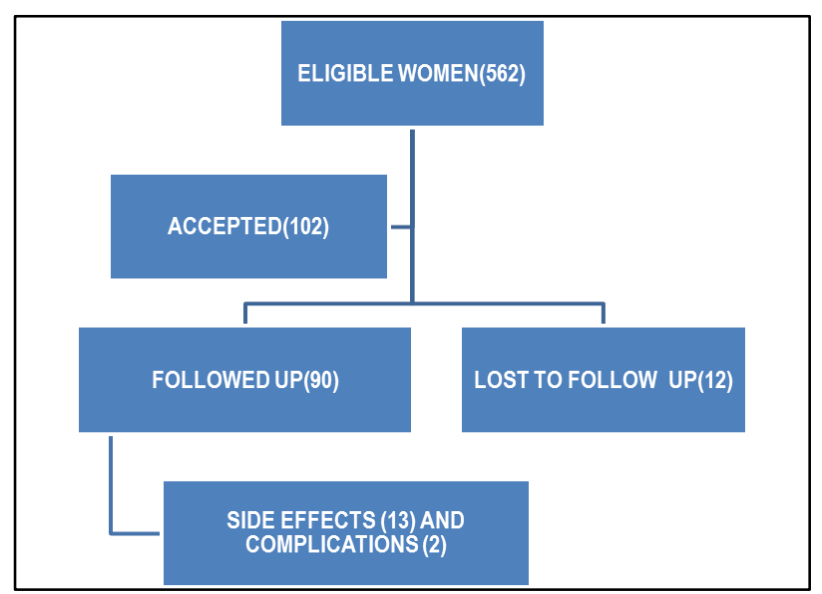

Figure 2: Flow chart showing recruitment of women and follow up in interval IUCD group. 
Table 1: Reasons for refusal of IUCD insertion by the women and their respective distribution.

\begin{tabular}{|lll|}
\hline Reasons for refusal of IUCD & No. & $\%$ \\
\hline Prefer to choose another method & 89 & 9.1 \\
\hline Satisfied with previous method & 126 & 12.9 \\
\hline Partner living outside & 116 & 11.9 \\
\hline Fear of pain and heavy bleeding & 257 & 26.3 \\
\hline No reason & 29 & 2.9 \\
\hline Religious beliefs & 87 & 8.9 \\
\hline Fears cancer & 9 & 0.09 \\
\hline Interfere with sex life & 18 & 1.8 \\
\hline Don't get pregnancy early & 58 & 5.9 \\
\hline Family and partner refusal & 185 & 18.9 \\
\hline Total & 974 & 100 \\
\hline
\end{tabular}

Fear of excessive pain and bleeding (26.3\%) was the main reason given by the women for refusal of IUCD insertion (Table 1).

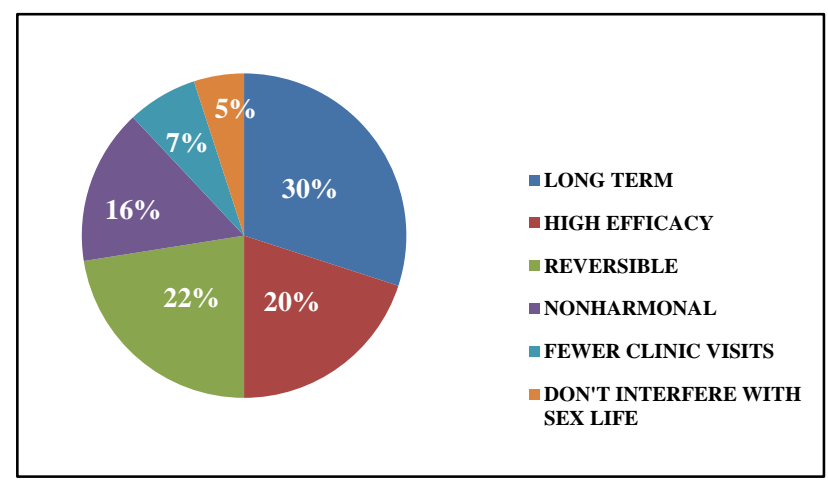

Figure 3: Reasons for accepting IUCD as a method of contraception.

Figure 3 was showing reasons for accepting IUCD as a method of contraception. The long term contraceptive effect $(30 \%)$ of IUCD was the main reason given by the women under study.

Table 2: The ease of insertion of PPIUCD and interval IUCD among the women.

\begin{tabular}{|lll|ll|}
\hline & $\begin{array}{l}\text { PPIUCD } \\
\text { (No.) }\end{array}$ & $\%$ & $\begin{array}{l}\text { Interval } \\
\text { IUCD } \\
\text { (No.) }\end{array}$ & $\%$ \\
\hline Easy & 412 & 97.17 & 84 & 82.3 \\
\hline Difficult & 12 & 2.8 & 18 & 17.6 \\
\hline Complicatio1 & 0 & 0 & 0 & 0 \\
\hline TOTAL & 424 & 100 & 102 & 100 \\
\hline
\end{tabular}

In Table 2, there was no complication at the time of insertion in both the groups. Table 3 shows the different type of side effects and their respective distribution in both groups.
Table 3: Shows the different type of side effects and their respective distribution in both groups.

\begin{tabular}{|lll|}
\hline Side effects & $\begin{array}{l}\text { PPIUCD } \\
(\text { No. }(\%))\end{array}$ & $\begin{array}{l}\text { Interval IUCD } \\
(\text { No. }(\%))\end{array}$ \\
\hline Excessive bleeding p/v & $25(40.3 \%)$ & $4(30.7 \%)$ \\
\hline Short cycles & $20(32.2 \%)$ & $3(23 \%)$ \\
\hline Discharge p/v & $13(20.9 \%)$ & $5(38.4 \%)$ \\
\hline Pain abdomen & $9(14.5 \%)$ & $1(7.7 \%)$ \\
\hline Total & 62 & 13 \\
\hline
\end{tabular}

Table 4: The placement of IUCD in the follow-up visits.

\begin{tabular}{|lll|}
\hline & $\begin{array}{l}\text { PPIUCD } \\
(\mathrm{No} .(\%))\end{array}$ & $\begin{array}{l}\text { Interval IUCD } \\
(\mathrm{No}=346) \\
(\mathbf{n}=90)\end{array}$ \\
\hline $\begin{array}{l}\text { IUCD in place } \\
\text { (strings visualized) }\end{array}$ & $306(88.4 \%)$ & $84(93.33 \%)$ \\
\hline $\begin{array}{l}\text { IUCD strings not } \\
\text { visualized }\end{array}$ & $34(9.8 \%)$ & $5(5.5 \%)$ \\
\hline Partial expulsion & $6(1.7 \%)$ & $1(1.1 \%)$ \\
\hline
\end{tabular}

Table 5: USG findings in case of non-visualization of strings.

\begin{tabular}{|ll|l|}
\hline $\begin{array}{l}\text { USG } \\
\text { findings }\end{array}$ & $\begin{array}{l}\text { PPIUCD (No. (\%)) } \\
(\mathrm{n}=34)\end{array}$ & $\begin{array}{l}\text { Interval IUCD } \\
(\mathrm{No} .(\%)) \\
(\mathrm{n}=5)\end{array}$ \\
\hline IUCD present & $14(41.1 \%)$ & $3(60 \%)$ \\
\hline IUCD absent & $20(58.8 \%)$ & $2(40 \%)$ \\
\hline
\end{tabular}

Table 6: Timing of expulsion of IUCD in both the groups.

\begin{tabular}{|llll|}
\hline Time & $\begin{array}{l}\text { Vaginal } \\
\text { PPIUCD } \\
\text { group }\end{array}$ & $\begin{array}{l}\text { Trans-caesarean } \\
\text { PPIUCD group }\end{array}$ & $\begin{array}{l}\text { Interval } \\
\text { group }\end{array}$ \\
\hline Within 7 days & 5 & 1 & 0 \\
\hline $\begin{array}{l}\text { Between 7 days } \\
\text { to 6 weeks }\end{array}$ & 9 & 2 & 2 \\
\hline After 6 weeks & 2 & 1 & 0 \\
\hline Total & 16 & 4 & 2 \\
\hline
\end{tabular}

Table 7: Continuation rates in both the groups at 6 months.

\begin{tabular}{|llll|}
\hline \hline $\begin{array}{l}\text { Type of IUCD } \\
\text { Vaginal }\end{array}$ & Removal Expulsion & $\begin{array}{l}\text { Continuation } \\
\text { rates }\end{array}$ \\
\hline $\begin{array}{l}\text { PPIUCD } \\
(\mathrm{n}=188)\end{array}$ & 25 & 16 & $147(78 \%)$ \\
\hline $\begin{array}{l}\text { Transcaeserean } \\
\text { PPIUCD } \\
(\mathrm{n}=158)\end{array}$ & 13 & 4 & $141(89 \%)$ \\
\hline Interval $(\mathrm{n}=90)$ & 15 & 2 & $73(81 \%)$ \\
\hline
\end{tabular}




\section{DISCUSSION}

The acceptance rate of PPIUCD was $30.34 \%$ and of interval IUCD was $18 \%$ (p-value <0.05). These high levels of acceptance were even despite lack of awareness, ignorance and lot of misconceptions regarding PPIUCD in the community. Majority of the women who accepted PPIUCD belonged to the age group 26-30 years (44\%). This was probably because most of the women who came to the hospital for delivery also belong to age group 26-30 years. This was similar in comparison to study of Rukiya et al which showed around $42.6 \%$ women belonging to the same age group. ${ }^{2}$ In primiparous women, PPIUCD is a highly preferred method (45\%) over interval IUCD (20\%) which indicates its use as a method of spacing. This is contrary to the finding of Grimes et al where they found higher acceptance in multiparous clients $(65.1 \%){ }^{3}$ IUCD is less popular in multigravidas in this area as these women are more inclined towards permanent method of sterilisation like tubectomy.

Majority of women included in the study had a minimal primary education ( $42 \%$ in PPIUCD and $48 \%$ in interval IUCD). It shows that education plays a pivotal role in understanding of contraceptive methods and chosing the right method by the client. However, around 30\% illiterate women also accepted IUCD as a method of contraception because of the good counseling and constant motivation done from the antenatal period. Our findings therefore suggest that sensitizing a women regarding family planning from the very beginning can increase the acceptance of IUCD significantly. This was similar to a study done by Safwat et al where women with no formal education had an acceptance of $9.4 \%$ while those with formal education were $19.4 \%{ }^{4}$

The chief reason for declining IUCD use was fear of excessive pain and bleeding (26.3\%) and refusal by partner or family (18.9\%). This reveals the importance of partner's involvement during family planning counseling and decision making. Counselling of couples right from the antenatal period must be made part of our routine antenatal check in order to sensitize them from the very beginning. Long term reversible method (32\%) and high efficacy $(21 \%)$ were the main reasons given for accepting IUCD.

There was no perforation or any other major complication at the time of insertion in both the groups. This is in accordance with the study of Rosales et al and El Beltagy et al where no perforations were observed. ${ }^{5,8}$

Majority of women in both the groups had easy insertion (97.17\% in PPIUCD and $82.3 \%$ in interval IUCD group). Only $2.8 \%$ women in PPIUCD group and $17.6 \%$ women in interval IUCD group had difficulty at the time of insertion which is statistically significant ( $p$-value $<0.05$ ). Expulsion rate of PPIUCD was $5.7 \%$ which is comparable to that of interval IUCD i.e. $2.22 \%$ (p-value $>0.05$ ) which signifies that with good insertion techniques and with trained insertors the expulsion rate of PPIUCD can be lowered. Rosales F et al in their study found expulsion rate of $16 \%$ and $2 \%$ for PPIUCD and interval IUCD respectively. ${ }^{5}$ In our study, spontaneous expulsion was seen in $16(8.5 \%)$ women in vaginal delivery group and $4(2.5 \%)$ women in trans-caeserian group which is significant statistically (p-value $<0.05$ ). This lower expulsion rate after trans-caesarean insertion as compared to vaginal insertion may be due to direct placement of IUCD at the fundus during caesarean section.

$17.9 \%$ (62/346) women in PPIUCD and 14.4\% (13/90) women in interval group had some side effects. However, there was no major complication in both the groups similar with the study of Eroglu et al where the rates of complications did not differ significantly between the two groups. ${ }^{6}$

Excessive bleeding per vaginum (40.3\%) was the main side effect in PPIUCD group whereas it was present in $30.7 \%$ in interval IUCD group. On the other hand, excessive discharge per vaginum (38.4\%) was the chief complaint in interval IUCD group and it was seen in $20.9 \%$ women in interval group whereas Celen $\mathrm{S}$ et al reported cumulative rates of bleeding equal to $11.4 \%$ and $8.2 \%$ respectively in PPIUCD and interval IUCD group. ${ }^{7}$

9.8\% women in PPIUCD and 5.55\% women in interval group complaint of missing strings. After doing per speculum examination and USG for localization of IUCD, expulsion was confirmed in 20 women of PPIUCD and 2 women of interval IUCD group. No case of PID or endometritis reported in our study. EL Beltagy et al also reported no increase in the incidence of PID after immediate postpartum IUCD insertion. ${ }^{8}$

Thirty-eight (10.9\%) women got their IUCD removed in PPIUCD group in comparison to $15(16.6 \%)$ women in interval group ( $\mathrm{p}$-value $>0.05$ ). Zhou $\mathrm{SW}$ et al showed the removal rate of $4.6 \%$ and $4.2 \%$ for vaginal PPL and trans-caesarean PPL respectively. ${ }^{9}$

The demand for IUCD removal was mainly for the complaint of excessive discharge $\mathrm{p} / \mathrm{v}$ in interval IUCD $(36 \%)$ and excessive vaginal bleeding (35\%) in PPIUCD group which were similar in comparison to other studies of Rukhiya et al, whereas the study of Iyenger et al showed that main reasons for removal were child death and family apposition. ${ }^{2,10}$

Continuation rates over a follow up period of 6 months were $83.2 \%$ in PPIUCD group and $81.1 \%$ in interval IUCD group (P-value >0.05). In PPIUCD group, continuation rates were higher in trans-caeserian route $(89 \%)$ in comparison to vaginal route $(78.4 \%)$ (P-value $<0.05)$ which is similar to the study of Celen et al who came out with continuation rates of $87.6 \%$ for PPIUCD. ${ }^{7}$ Tatum et al showed continuation rates of 
around $80 \%$ in PPIUCD after 6 months of insertion in their study. ${ }^{11}$

\section{CONCLUSION}

There is lack of awareness and lot of misconceptions regarding PPIUCD in the community. Despite this the acceptance rate was significantly high in our study. This shows the importance of good counselling from the antenatal period. Still there is need to develop strategies to increase public awareness of the PPIUCD through different media sources.

In the study, primigravida had greater acceptance of the PPIUCD. However, multigravidas are more driven towards permanent method of contraception like tubectomy. The government policies should focus on promoting PPIUCD as a long term, reversible method of contraception as it is more cost effective than sterilization.

Acceptance was higher among women who had minimal primary education which reflects that education has a pivotal role to play in the understanding and acceptance of contraceptive measures. Higher rate of expulsion were seen in PPIUCD as compared to interval though not statistically significant. Continuation rates over a follow up period of 6 months were higher in PPIUCD (83.2\%) than interval IUCD $(81.1 \%)$. Continuation rates in transcaeserian group were significantly higher than vaginal group.

Hence, we can conclude that PPIUCD is a safe, effective, reversible, long sterm method of contraception and it should be promoted as a method of long term reversible contraception in India. It should be a part of maternal/newborn/reproductive health package and we as a health care provider should utilize JSY (Janani Suraksha Yojna) scheme to decrease the unmet need of contraception in women delivering in our hospital.

Funding: No funding sources

Conflict of interest: None declared

Ethical approval: The study was approved by the Institutional Ethics Committee

\section{REFERENCES}

1. National rural health mission ministry of health and family welfare Government of India. JSY. Available at http:// www. mohfw.nic.in/ layout_0906. pdf. Accessed on 18 October 2014.

2. Abdulwahab R, Ali M. Dept of Obstetrics and Gynaecology,Muhimbili University of Health and Allied Sciences, Tanzania, November 2012.

3. Grimes D, Schulz K, Van VH, Stanwood N. Immediate postpartum insertion of IUCD. Cochrane Database Rev. 2003;1(4):23-7.

4. Safwat A, Mohamed MA, Kamel OM. Acceptability for the use of postpartum intrauterine contraceptive devices: assiut experience. Med Princ Pract. 2003; 12:70-5.

5. Bonilla RF, Aguilar ZME, Cazares ML, Hernandez OME, Luna RMA. Factors for expulsion of intrauterine device TCu380 a applied immediately postpartum and after a delayed period. Rev Med Inst Mex Seguro Soc. 2005;43:5-10.

6. Kafiye E, Greenslade AG. Comparison of efficacy and complication of IUCD insertion in immediate post placental, early postpartum period with interval period. 1 year follow up period. Contraception. 2006;74:376-81.

7. Celen S, Moroy P, Sucak A, Aktulay A, Danişman N. Clinical outcomes of early postplacental insertion of intrauterine contraceptive devices. Contraception. 2004;69:279-82.

8. Beltagy NS, Darwish EA, Kasem MS, Hefila NM. Comparison Between Cupper T380 Iud and Multiload 375 Iud in early post-partum insertion. Middle East Fertility Society J. 2010;16:143-8.

9. Zhou SW, Chi IC. Immediate postpartum IUD insertions in a Chinese hospital a two year followup. Int J Gynaecol Obstet. 1991;35:157-64.

10. Iyenger K, Ayenger SD. The Copper-T 380A IUD: a ten-year alternative to female sterilisation in India. Reproductive Health Matters. 1992;16:125-33.

11. Tatum HJ, Beltran RS, Ramos R, Van KH, Sivin I, Scmidt FH, Immediate postplacental insertion of gyne t 380 and gyne t 380 postpartum iucd. randomised study. Am J Obst Gynae. 1996;175:1231-5.

12. Postpartum IUCD Reference Manual, Ministry of Health and Family Welfare, India. November 2010.

Cite this article as: Tyagi S, Aditya V, Srivastava $\mathrm{R}$, Gupta G. Changing trends in intrauterine contraceptive device: from interval intrauterine contraceptive device to postpartum intrauterine contraceptive device: a prospective observational study in a tertiary care hospital in eastern Uttar Pradesh. Int J Reprod Contracept Obstet Gynecol 2016;5:2104-8. 